EFICIÊNCIA NA ALOCAÇÃO DOS GASTOS PÚBLICOS NA EDUCAÇÃ̃ ${ }^{1}$

\author{
EFFICIENCY IN THE ALLOCATION OF PUBLIC SPENDING ON EDUCATION
}

\title{
EFICIENCIA EN LA ASIGNACIÓN DEL GASTO PÚBLICO EN EDUCACIÓN
}

Viviane Theiss, Doutoranda em Ciências Contábeis pela Universidade Federal do Paraná UFPR. Av. Prefeito Lothário Meissner, 632, 1o. Andar, Campus III, Jardim Botânico. CEP 80210-170 - Curitiba, Paraná. URL da Homepage: www.ppgcontabilidade.ufpr.br. E-mail: theissviviane@gmail.com.

Jorge Eduardo Scarpin, Professor Doutor em Ciências Contábeis pela Universidade Federal do Paraná - UFPR. Endereço profissional: Av. Prefeito Lothário Meissner, 632, 1o. Andar,

Campus III, Jardim Botânico. CEP 80210-170 - Curitiba, Paraná. URL da Homepage: www.ppgcontabilidade.ufpr.br. E-mail: jscarpin@gmail.com

Delci Grapegia Dal Vesco, Professora Doutora em Ciências Contábeis pela Universidade Estadual do Oeste do Paraná - UNIOESTE. Endereço profissional: Rua Universitária, 2069 Jardim Universitário. CEP 85819-110. Cascavel - Paraná. URL da Homepage: http://www.unioeste.br/. E-mail: delcigrape@gmail.com

Nayane Thais Krespi, Doutoranda em Métodos Numéricos em Engenharia pela Universidade Federal do Paraná - UFPR. Endereço profissional: Av. Prefeito Lothário Meissner, 632, Campus III, Jardim Botânico. CEP 80210-170 - Curitiba, Paraná.

URL da Homepage: www.ppgcontabilidade.ufpr.br. E-mail: nayanethais@ hotmail.com

\section{RESUMO}

O objetivo deste estudo é analisar a alocação de recursos econômicos e externalidades positivas na educação de países da América Central, do Sul e México. O método utilizado caracteriza-se, quanto aos objetivos uma pesquisa descritiva, documental quanto aos procedimentos, com uma abordagem do problema quantitativo, com a aplicação da Data Envelopment Analysis - DEA. A amostra compõe os países da América Latina, sendo 1 país da América do Norte, 12 países da América Central e 9 países da América do Sul, escolhidas pela sua proximidade regional, semelhanças econômicas e culturais. Com dados extraídos da plataforma UNDATA e armazenados em planilha eletrônica para posterior análise. Os resultados informam que o Brasil encontra-se entre os países que obtiveram eficiência máxima, em que é possível afirmar que, para o grupo de países analisados, este país está obtendo tantas externalidades quanto é possível para as despesas que possui com educação. Ressalta-se que Cuba obteve a menor eficiência da pesquisa, fato que pode ter sua explicação no tipo de economia deste país, que se encontra inserido no regime socialista. Porém, essa

\footnotetext{
${ }^{1}$ Artigo submetido em 10/10/2014, revisado em 19/10/2014, aceito em 19/12/2014 e divulgado em 30/06/2015 pelo Editor João Carlos Hipólito Bernardes do Nascimento, após double blind review.

GєCont, v.2, n. 1, Floriano-PI, Jan-Jun. 2015.
} 
justificativa não altera o resultado encontrado, ou seja, Cuba não está eficiente na alocação de recursos econômicos em relação ao incremento das externalidades positivas na educação. Desta forma, é possível concluir que existe diferença de eficiências na alocação de recursos econômicos em relação ao incremento das externalidades positivas na educação dos países da América Central, do Sul e México.

Palavras-chaves: Despesas públicas com educação; Externalidades positivas; Análise Envoltória de Dados.

\begin{abstract}
The aim of this study is to analyze the allocation of economic resources and positive externalities in the countries of Central America, South America and Mexico education. The method used in this research is characterized as the objectives a descriptive, documentary about the procedures, with a quantitative approach to the problem, with the application of Data Envelopment Analysis - DEA. The sample comprises in 1 country in North America, 12 countries of Central America and 9 countries in South America, chosen for their regional proximity, economic and cultural similarity. With data extracted from UNDATA platform and compiled in a spreadsheet for further analysis. The results report that Brazil is among the countries which have maximum efficiency, it is possible to say that, for the group of countries analyzed, this country is getting as many externalities as it is possible for the expenses it has with education. It is emphasized that Cuba obtained the lower efficiency of the research, which may have their explanation in this type of economy, which is inserted into the socialist regime. But this justification does not change the results found, ie, Cuba is not efficient in the allocation of economic resources in relation to the increase of positive externalities in education. Thus, we conclude that there is difference in efficiencies in the allocation of economic resources in relation to the increase of positive externalities in education from Central America, South America and Mexico.
\end{abstract}

Keywords: Public expenditure on education; Positive externalities; Data envelopment analysis.

\title{
RESUMEN
}

El objetivo de este estudio es analizar la asignación de recursos económicos y externalidades positivas en los países de América Central, América del Sur y de la educación de México. El método se caracteriza en que los objetivos de un estudio descriptivo, documental sobre los procedimientos, con una aproximación cuantitativa al problema, con la aplicación del Análisis Envolvente de Datos - DEA. La muestra consta de 1 país de América del Norte, 12 países de América Central y 9 países de América del Sur, elegidos por su proximidad al territorio, la similitud económica y cultural. Con los datos extraídos de la plataforma UNDATA y compilados en una hoja de cálculo para su posterior análisis. Los resultados indican que Brasil está entre los países que cuentan con la máxima eficiencia, es posible decir que, para el conjunto de países analizados, este país es cada vez mayor número de externalidades, ya que es posible que los gastos que tiene con la educación. Se enfatiza que Cuba obtuvo la menor eficiencia de la investigación, que puede tener su explicación en este tipo de economía, que se inserta en el régimen socialista. Pero esta justificación no cambia los resultados encontrados, es decir, Cuba no es eficiente en la asignación de los recursos económicos en relación con el aumento de las externalidades positivas en la educación. Por lo tanto, llegamos a la conclusión de que existe diferencia en la eficiencia en la asignación de 
los recursos económicos en relación con el aumento de las externalidades positivas en la educación de América Central, América del Sur y México.

Palabras clave: el gasto público en educación; Las externalidades positivas; Análisis envolvente de datos.

\section{INTRODUÇÃO}

educação tem um papel decisivo para a economia, como mostram estudos em

A que o crescimento e a educação de um país estão altamente correlacionados, como abordam (LUCAS, 1988; ROMER; WEIL, 1992; BILS; KLENOW, 2000; RODRIGUES, 2004), visto ser a educação um tipo de bem que todos desejam o seu uso, maximizado pelo bem que proporciona à sociedade (SAMUELSON, 1954).

Lucas (1988) propôs que o capital humano é impulsor do crescimento em alternativa ao progresso tecnológico. Para o autor, os indivíduos dividem o seu tempo em adquirir conhecimentos por meio da escola, aumentando consequentemente o seu nível de capital humano. O acréscimo de capital humano de um indivíduo não beneficia apenas esse indivíduo, mas a sociedade em geral porque o nível agregado de capital humano contribui para o aumento da produtividade dos outros fatores na economia (RODRIGUES, 2004).

Conforme Piffaut (2009), o PIB per capita, ao mesmo tempo em que está negativamente associado com a desigualdade de educação, pode estar positivamente relacionado com a média de anos de escolaridade da força de trabalho. Martins e Jin (2010) explanam que os trabalhadores beneficiam-se da educação de seus colegas de trabalho, ou seja, os trabalhadores educados transferem parte de suas habilidades gerais para iletrados trabalhadores. Segundo os autores, existem retornos significativos para os trabalhadores com menor escolaridade, mas não aos seus colegas mais instruídos.

A educação pode destacar positivamente uma sociedade, como descreve Lochner e Moretti (2004) com a redução da criminalidade, por elevar os custos de oportunidades, aumentando os rendimentos legais. Pode também influenciar a distribuição de renda, o crescimento econômico de um país, desenvolvimento tecnológico, entre outros aspectos, como apresentam os estudos de Bils e Klenow (2000); Tokman (2004); Hanushek e Woessmann (2008); e Piffaut (2009).

Nesse sentido, é possível apresentar uma hipótese para esta pesquisa:

$H_{0}$ - Não há diferença de eficiências na alocação de recursos econômicos em relação ao incremento das externalidades positivas na educação dos países da América Central, do Sul e México.

Para Rodrigues (2004), os impactos de investimentos em educação diferem entre países, pelos diferentes contextos institucionais existentes em cada país. Por estes motivos, o presente estudo investiga a seguinte questão problema: Qual a eficiência na alocação de recursos econômicos em relação ao incremento das externalidades positivas na educação dos países da América Latina? Deste modo, o objetivo deste estudo foi analisar a alocação de recursos econômicos e externalidades positivas na educação de países da América Central, do Sul e México.

Este artigo caracteriza como descritivo, com um procedimento de pesquisa documental e abordagem quantitativa do problema. A relevância deste estudo está em medir a eficácia e eficiência, por meio do método Data Envelopment Analysis - DEA que indicadores 
econômicos que apresentam relação com os indicadores sociais de educação em diferentes países latino-americanos, ao indicar a performance em tal ordem que consolida em um único indicador as diversas perspectivas que sejam consideradas para análise.

Este artigo está estruturado na seguinte ordem, inicialmente apresenta-se esta introdução, em seguida, o referencial teórico com a abordagem da externalidade e bens públicos, externalidades e a educação, e estudos correlatos. No terceiro capítulo, apresentamse os procedimentos metodológicos e explicações do método de análise utilizado. No quarto capítulo, a análise dos resultados e finalmente, as considerações finais.

\section{REVISÃO DA LITERATURA}

Neste capítulo são apresentados aspectos da externalidade e bens públicos, da mesma forma que as externalidades positivas que a educação proporciona. Finalmente, estudos correlatos sobre o tema.

\subsection{Externalidades e Bens Públicos}

O termo externalidades foi inicialmente conceituado por Marshall (1984) ao avaliar que as economias externas poderiam ser alcançadas pela concentração de entidades menores e similares em determinados locais. Segundo Samuelson (1954), diversos economistas não negligenciam a suposição da teoria dos gastos públicos, o que leva ao domínio da "sociologia" ou "política de bem-estar".

A regulação da economia por meio de taxas não seria suficiente para regular o mercado, por necessitar de uma intervenção maior do governo. Conforme Kon (1997), a intervenção governamental no sistema econômico, objetiva-se em criar, manter e aprimorar as externalidades positivas e a eliminar, corrigir e controlar as externalidades negativas (SAMUELSON, 1954).

Conforme Pindyck e Rubinfeld (2010, p. 576), a externalidade é a "ação de um produtor ou consumidor que afeta outros produtores ou consumidores, mas que não é considerada preço de mercado". De acordo com Mankiw (2005), as externalidades ocorrem quando as ações de uma pessoa impactam sobre o bem-estar de outras que não fazem parte de ação. Devido ao fato das externalidades não estarem refletidas nos preços de mercado, acaba se tornando uma das causas da ineficiência econômica em curto a longo prazo (PINDYCK; RUBINDELD, 2010).

Segundo Scarpin e Slomski (2007), na presença de externalidades, o interesse da sociedade em relação a um resultado de mercado vai além do bem-estar de seus compradores e vendedores. Dessa maneira, os autores elucidam que o equilíbrio de mercado não consegue maximizar seu benefício total para a sociedade. Um exemplo é a escolaridade caracterizada por Iranzo e Peri (2009), considerado um investimento valioso, por provocar um efeito positivo para a sociedade como um todo (externalidades positivas).

O fornecimento de bens e serviços públicos cria externalidades positivas para uma parcela da sociedade, porém pode ocasionar problemas quando ultrapassam um tamanho considerado "ótimo" de concentração urbana, o que leva a deterioração dos bens e serviços públicos (SAMUELSON, 1954; KON, 1997). A deterioração ocorre de uma forma mais lenta, pois cada tipo de bem ou serviço público apresenta uma capacidade ou limite, além do que a interferência mútua entre os consumidores se torna notável e aumenta desproporcionalmente a oferta pelo governo (SAMUELSON, 1954; KON, 1997). 


\subsection{Externalidades e Educação}

Dentre os fenômenos que acarretam em externalidades positivas sobre o mercado de trabalho e na sociedade, destaca-se educação. Uma das externalidades positivas que a educação proporciona, de acordo com Lochner e Moretti (2004), é reduzir a criminalidade, por elevar os custos de oportunidades da sociedade, aumentando os rendimentos legais. Conforme os autores, a educação faz com que a sociedade se torne mais paciente ou mais avessa ao risco de realizar algum crime, o que reduz a propensão para cometer crimes.

De acordo com os mesmos argumentos, Tokman (2004) apresenta que a educação é o principal determinante do capital humano e um fator altamente relevante para o crescimento dos países, graças aos seus efeitos diretos (fator produtivo) e indiretos (processo de produção). Fato também estudado por Bils e Klenow (2000); Hanushek e Woessmann (2008); e Piffaut (2009) ao analisarem o impacto da escolaridade sobre a distribuição de renda e no crescimento econômico.

Tokman (2004) ainda descreve que a educação contribui com outros fatores, como o desenvolvimento tecnológico, ocasionando uma abertura comercial dos recursos naturais e entre outros.

\subsection{Estudos correlatos}

Os esforços em torno da compreensão da relação entre os indicadores econômicos com os indicadores sociais de educação geraram diversas pesquisas tanto no ambiente nacional como no ambiente internacional.

Bils e Klenow (2000) examinaram a capacidade do capital humano em desempenhar um papel importante para o crescimento da escolaridade. Para isso, foi utilizado um modelo para quantificar a força do efeito da escolaridade sobre o crescimento, no qual mede o impacto da escolaridade sobre o capital humano. Os resultados mostraram que, o impacto da escolaridade sobre o crescimento é menor que um terço do relacionamento cross-country empírico, resultado fraco demais para explicar relação entre escolaridade e crescimento.

Os autores Hanushek e Woessmann (2008) revisaram o papel da educação na promoção do bem-estar econômico, por meio de testes de especificações alternativas e hipóteses sobre os determinantes dos resultados. A educação para este estudo é uma ampla variedade de insumos e processos que induzem ao conhecimento individual, referindo-se especificamente nas habilidades cognitivas. Os achados mostram que há fortes indícios de que as habilidades cognitivas da população estão fortemente relacionadas com rendimento individual, com a distribuição de renda e com o crescimento econômico.

Piffaut (2009) analisou o papel desempenhado pela educação na experiência de crescimento econômico do Chile, por fornecer uma análise de séries temporal econométricas dos determinantes do crescimento, bem como uma análise transversal que inclui o Chile como um dos muitos países cujo crescimento experiência é examinado. Os resultados obtidos indicam uma distribuição desigual da educação no país, o que pode impedir seu crescimento econômico. O PIB per capita mostrou-se negativamente associado com a desigualdade da educação, todavia foi positivamente relacionado com a média de anos de escolaridade da força de trabalho, após o controle de níveis de renda inicial.

Mare et al. (2011) avaliaram aspectos de qualidade em programas de educação superior na Romênia. O objetivo foi estabelecer o nível de satisfação dos estudantes de mestrado em relação ao processo educativo em que estão envolvidos, por meio de métodos de análise de dados estatísticos, capazes de colocar em luz um nível significativamente elevado de satisfação dos estudantes de mestrado pesquisados. Os resultados da pesquisa informam 
que a maioria da amostra apresentou o conteúdo prático dos cursos e que a grande parte dos entrevistados aprecia os estudos de caso real.

\section{PROCEDIMENTOS METODOLÓGICOS}

O presente estudo descritivo foi realizado por meio de pesquisa documental, com abordagem quantitativa do problema. A característica descritiva decorre do fato de que o estudo tem como finalidade analisar a alocação de recursos econômicos e externalidades positivas na educação de países da América Central, do Sul e México. Segundo Vergara (2000, p. 47), "a pesquisa descritiva expõe características de determinada população ou de determinado fenômeno".

Quanto ao procedimento utilizado, o mesmo deu-se por meio de pesquisa documental, conforme proposto por Marconi e Lakatos (2010, p. 176), "a característica da pesquisa documental é que a fonte de dados está restrita a documentos escritos ou não, chamados de fontes primárias." Os dados foram extraídos dos relatórios disponibilizados pela Organização das Nações Unidas - ONU em uma plataforma chamada UNDATA.

No que se refere à abordagem do problema, a pesquisa se constitui como quantitativa, uma vez que, após ter quantificados e mensurados os dados, foi aplicada uma técnica estatística para realização da análise dos dados (MARTINS; THEÓPHILO, 2007).

\subsection{População e amostra}

A população de pesquisa compreende os países da América do Sul, América Central juntamente com o México, perfazendo um total de 33 países. Por sua vez, a amostra do estudo é composta por 22 países, os quais possuíam os dados necessários para a realização da pesquisa disponíveis na data da coleta. O Quadro 1 descreve os países que compõem a amostra da pesquisa.

Quadro 1 - Descrição da amostra

\begin{tabular}{|c|c|c|c|c|c|}
\hline & País & Localização & & País & Localização \\
\hline 01 & Antígua e Barbuda & América Central & 12 & Guatemala & América Central \\
\hline 02 & Argentina & América do Sul & 13 & Jamaica & América Central \\
\hline 03 & Barbados & América Central & 14 & México & América do Norte \\
\hline 04 & Bolívia & América do Sul & 15 & Panamá & América Central \\
\hline 05 & Brasil & América do Sul & 16 & Paraguai & América do Sul \\
\hline 06 & Chile & América do Sul & 17 & Peru & América do Sul \\
\hline 07 & Colômbia & América do Sul & 18 & República Dominicana & América Central \\
\hline 08 & Costa Rica & América Central & 19 & Santa Lúcia & América Central \\
\hline 09 & Cuba & América Central & 20 & São Vicente e Granadinas & América Central \\
\hline 10 & Dominica & América Central & 21 & Uruguai & América do Sul \\
\hline 11 & El Salvador & América Central & 22 & Venezuela & América do Sul \\
\hline
\end{tabular}

Fonte: Dados da pesquisa. 
O Quadro 1 evidencia que a composição da amostra se dá por 12 países da América Central, 9 países da América do Sul e 1 (um) país da América do Norte, o México, totalizando 22 países. A escolha da amostra justifica-se pela proximidade regional dos países e principalmente em função da semelhança econômica e cultural encontrada nestes países.

Os dados utilizados na pesquisa foram coletados no endereço eletrônico da plataforma UNDATA, cuja responsabilidade é da ONU. Após a coleta, os dados foram armazenados em planilha eletrônica para posterior análise. Os dados coletados têm como referência o ano mais recente cujos dados estavam disponíveis na data da pesquisa.

\subsection{Método de análise envoltória de dados}

Os dados utilizados na presente pesquisa estão descritos no Quadro 1. Estes foram obtidos junto à plataforma UNDATA, que por sua vez recebeu as informações relativas à educação com a Organização das Nações Unidas para a Educação, a Ciência e a Cultura UNESCO.

Quadro 2 - Variáveis utilizadas na pesquisa

\begin{tabular}{|c|c|c|}
\hline & Grupo & Variáveis \\
\hline Input & $\begin{array}{l}1 \\
\text { Despesas com educação }\end{array}$ & $\begin{array}{l}1.1 \text { - Despesas públicas com educação (\% do PIB); } 1.2 \text { - Despesas } \\
\text { públicas com educação ( } \% \text { do rendimento bruto nacional); } 1.3 \text { - } \\
\text { Despesas públicas correntes com educação (\% das despesas públicas } \\
\text { com educação); } 1.4 \text { - Despesas com educação no ensino médio (\% das } \\
\text { despesas correntes totais com educação); } 1.5 \text { - Despesa pública total } \\
\text { com educação por aluno de ensino fundamental (\% do PIB per capta); } \\
1.6 \text { - Despesa pública total com educação por aluno de ensino médio } \\
\text { (\% do PIB per capta); }\end{array}$ \\
\hline \multirow{3}{*}{ Output } & $\begin{array}{l}2 \\
\text { Taxas brutas }\end{array}$ & $\begin{array}{l}\text { 2.1 - Taxa bruta de admissão para o último ano do ensino fundamental } \\
\text { - I segmento; } 2.2 \text { - Taxa bruta de admissão para o último ano do } \\
\text { ensino fundamental - I segmento (em relação ao Indicador de } \\
\text { progresso genuíno - GPI); }\end{array}$ \\
\hline & $\begin{array}{l}3 \\
\text { Expectativa de vida } \\
\text { escolar }\end{array}$ & $\begin{array}{l}3.1 \text { - Expectativa de vida escolar no pré-primário (anos); } 3.2 \text { - } \\
\text { Expectativa de vida escolar no nível } 1 \text { da ISCED; } 3.3 \text { - Expectativa de } \\
\text { vida escolar nos níveis } 1 \text { a } 3 \text { da ISCED; } 3.4 \text { - Expectativa de vida } \\
\text { escolar nos níveis } 1 \text { a } 3 \text { da ISCED (em relação ao GPI); } 3.5 \text { - } \\
\text { Expectativa de vida escolar nos níveis } 2 \text { e } 3 \text { da ISCED; } 3.6 \text { - } \\
\text { Expectativa de vida escolar nos níveis } 5 \text { e } 6 \text { da ISCED (em relação ao } \\
\text { GPI). }\end{array}$ \\
\hline & $\begin{array}{l}4 \\
\text { Reprovações }\end{array}$ & $\begin{array}{l}4.1 \text { - Percentual de repetentes no ensino fundamental - I segmento; } \\
4.2 \text { - Percentual de repetentes no ensino fundamental - I segmento (em } \\
\text { relação ao GPI). }\end{array}$ \\
\hline
\end{tabular}

Fonte: Dados da pesquisa.

É possível observar, conforme evidenciado no Quadro 2, as variáveis pertencentes ao grupo de despesas com educação foram consideradas outputs, ao passo que as variáveis integrantes dos demais grupos foram consideradas inputs para proceder na análise estatística através da análise envoltória dos dados (DEA).

Entre as variáveis, é possível identificar a sua relação com o Indicador de progresso genuíno - GPI, de acordo com Tayra e Ribeiro (2006), o GPI é semelhante ao cálculo do Produto Interno Bruto - PIB, todavia, deduz alguns fatores utilizados no cálculo do PIB, pois seu foco é em critérios sociais, ambientais e econômicos. Para os autores, estão inclusos no cálculo do GPI, gastos como consumo das pessoas, ao invés de focar em gastos financeiros, como despesas e investimento do governo, entre outros. 
De acordo com Banker, Charnes e Cooper (1984), o método de análise envoltória dos dados (DEA) é a utilização da programação matemática para obter avaliações ex post facto da eficiência relativa dos resultados dos gestores, que tenham sido planejados ou executados. Esse modelo apresenta inputs, que são os insumos ou recursos, outputs, que são os produtos e fronteira de produção, que são definidas a partir da quantia máxima de outputs que podem ser obtidos dados os inputs utilizados.

O modelo tem como objetivo identificar a eficiência de um indicador comparando-o com os melhores desempenhos observados (MACEDO; BARBOSA; CAVALCANTE, 2009). Ainda segundo esses autores, as análises realizadas por meio do DEA fornecem indicadores que podem variar de 0 a 1 , sendo que somente os indicadores que obtêm índice de eficiência máximo é que fazem parte da fronteira de eficiência, ou seja, são de fato eficientes.

Dois são os modelos DEA mais utilizados em aplicações práticas, são eles: o CCR (CHARNES; COOPER; RHODES, 1978) e o BCC (BANKER; CHARNES; COOPER, 1984). O primeiro modelo, também conhecido por CRS (Constant Returns to Scale), analisa eficiência total, determinando as fronteiras de eficiência e ainda, a que distância dessa fronteira estão às unidades ineficientes. Em seguida, o segundo também denominado VRS (Variable Returns to Scale), o qual "permite a projeção de cada DMU ineficiente sobre a superfície de fronteira (envoltória) determinada pelas DMUs eficientes de tamanho compatível" (MACEDO; BARBOSA; CAVALCANTE, 2009, p. 3).

No caso da presente pesquisa, foi utilizado o modelo CCR para proceder à análise dos dados que, tradicionalmente, é determinado pela razão entre outputs por inputs. Neste trabalho, optou-se pelo modelo CCR por apresentar retornos constantes de escala, ou seja, qualquer variação nos insumos leva a uma variação proporcional nos produtos (CHARNES; COOPER; RHODES, 1978). No modelo CCR, a fronteira de eficiência é determinada por uma reta que corta a origem e passa por um dos pontos que representa uma DMU, sendo que o coeficiente angular desta reta deve ser o máximo comparado com as demais.

Os indicadores que compõem o grupo 1 (despesas com educação) foram utilizados como inputs, ao passo que os indicadores dos grupos 2 (taxas brutas), 3 (expectativa de vida escolar) e 4 (reprovações) foram considerados outputs. Dessa forma, procedeu-se o cálculo do DEA objetivando mensurar a eficiência dos investimentos em educação dos países analisados.

\section{APRESENTAÇÃO E ANÁLISE DOS RESULTADOS}

Este estudo teve como objetivo analisar a eficiência dos indicadores econômicos sobre os indicadores sociais de educação dos países da América Central, do Sul e México, por meio da análise envoltória de dados - DEA. A Tabela 1 apresenta a estatística descritiva das variáveis, com o intuito de analisar as características gerais da distribuição das variáveis. 
Tabela 1 - Estatística descritiva das variáveis

\begin{tabular}{|c|c|c|c|c|c|c|c|}
\hline & Grupo & Variáveis & Mínimo & Máximo & Média & Mediana & Desvio-padrão \\
\hline \multirow{6}{*}{ Input } & \multirow{6}{*}{1} & 1.1 & 2.55 & 13.38 & 5.03 & 4.62 & 2.36 \\
\hline & & 1.2 & 2.64 & 13.58 & 5.28 & 4.79 & 2.45 \\
\hline & & 1.3 & 0.00 & 100.00 & 86.13 & 92.39 & 20.89 \\
\hline & & 1.4 & 0.00 & 25.23 & 3.67 & 0.00 & 7.37 \\
\hline & & 1.5 & 0.00 & 44.17 & 13.89 & 13.67 & 8.22 \\
\hline & & 1.5 & 6.19 & 51.87 & 17.47 & 14.42 & 10.00 \\
\hline \multirow{10}{*}{ Output } & \multirow{2}{*}{2} & 2.1 & 74.57 & 115.10 & 96.32 & 96.45 & 8.99 \\
\hline & & 2.2 & 0.00 & 1.30 & 0.97 & 1.01 & 0.23 \\
\hline & \multirow{6}{*}{3} & 3.1 & 0.00 & 3.10 & 1.70 & 1.67 & 0.69 \\
\hline & & 3.2 & 5.22 & 8.67 & 6.68 & 6.68 & 0.68 \\
\hline & & 3.3 & 10.17 & 13.40 & 11.68 & 11.78 & 0.93 \\
\hline & & 3.4 & 0.92 & 1.07 & 1.00 & 1.01 & 0.04 \\
\hline & & 3.5 & 2.80 & 6.98 & 4.91 & 4.98 & 0.90 \\
\hline & & 3.6 & 0.00 & 1.09 & 0.96 & 1.01 & 0.22 \\
\hline & \multirow{2}{*}{4} & 4.1 & 0.00 & 18.67 & 5.18 & 4.19 & 4.20 \\
\hline & & 4.2 & 0.00 & 1.24 & 0.64 & 0.69 & 0.27 \\
\hline
\end{tabular}

Fonte: Dados da pesquisa.

Conforme evidenciado na Tabela 1, das variáveis consideradas outputs, a que apresentou um maior desvio-padrão, isto é, uma maior discrepância entre o valor mínimo e o valor máximo dos dados, foi a 1.3 (despesas públicas correntes com educação). Essa observação sugere que os países analisados não possuem um valor padrão para investimentos em educação, ressalta-se ainda, que os países analisados possuem tamanhos diferentes, fator que pode levar a algumas diferenças de valores.

Por sua vez, ainda no grupo 1 de variáveis (despesas com educação), o menor desviopadrão é observado na variável 1.1 (despesa com educação em \% do PIB), fato que descarta a diferença de tamanho entre os países analisados e apresenta uma boa confiabilidade de que os países investem basicamente o mesmo valor em educação, cada qual proporcional a sua geração de riqueza anual.

Ao analisar o desvio-padrão das variáveis componentes do grupo considerado inputs, é possível verificar que o maior valor diz respeito a variável 2.1 (taxa bruta de admissão para o último ano do ensino fundamental - II segmento) apresentando desvio-padrão de 8,99. As demais variáveis apresentaram valores muito baixos de desvio-padrão. Como as variáveis que foram consideradas inputs são, em sua maioria, apresentadas em \%, também é descartado o fator tamanho, o que torna a análise mais precisa e real.

Destaca-se ainda, que para todas as variáveis analisadas obteve-se valores médios muito próximos dos valores medianos, principalmente no grupo dos inputs, o que mais uma vez transparece a homogeneidade dos dados analisados, garantindo assim, a qualidade da análise realizada por meio do DEA.

A Tabela 2 evidencia a análise de eficiência da aplicação dos recursos financeiros públicos na educação realizada por meio do cálculo do DEA. 
Tabela 2 - Eficiência dos países

\begin{tabular}{|c|c|c|c|}
\hline NO & DMU & Localização & Score \\
\hline 1 & Antígua e Barbuda & América Central & 1 \\
\hline 3 & Barbados & América Central & 1 \\
\hline 6 & Brasil & América do Sul & 1 \\
\hline 12 & El Salvador & América Central & 1 \\
\hline 13 & Guatemala & América Central & 1 \\
\hline 16 & Panamá & América Central & 1 \\
\hline 18 & Peru & América do Sul & 1 \\
\hline 21 & Uruguai & América do Sul & 1 \\
\hline 22 & Venezuela & América do Sul & 1 \\
\hline 7 & Chile & América do Sul & 0.802 \\
\hline 15 & México & América do Norte & 0.733 \\
\hline 8 & Colômbia & América do Sul & 0.718 \\
\hline 17 & Paraguai & América do Sul & 0.714 \\
\hline 11 & Dominica & América Central & 0.683 \\
\hline 5 & Bolívia & América do Sul & 0.669 \\
\hline 9 & Costa Rica & América Central & 0.630 \\
\hline 14 & Jamaica & América Central & 0.538 \\
\hline 2 & Argentina & América do Sul & 0.536 \\
\hline 19 & Santa Lúcia & América Central & 0.514 \\
\hline 4 & Belize & América Central & 0.511 \\
\hline 20 & São Vicente e Granadinas & América Central & 0.506 \\
\hline 10 & Cuba & América Central & 0.275 \\
\hline
\end{tabular}

Fonte: Dados da pesquisa.

Conforme exposto na Tabela 2, 9 países obtiveram eficiência máxima, sendo 5 países da América Central e 4 da América do Sul. São os países: Antígua e Barbuda, Barbados, Brasil, El Salvador, Guatemala, Panamá, Peru, Uruguai e Venezuela. Este resultado sugere que as despesas com educação (inputs) estão rendendo os melhores resultados possíveis (outputs) quando comparados com esse grupo de países.

Em estudo realizado por Bils e Klenow (2000), os autores afirmam existir correlação positiva entre a escolaridade e a taxa de crescimento do PIB, fator que pode explicar o resultado exposto na Tabela 2, visto que quanto maior o crescimento do PIB espera-se que maiores sejam as despesas com educação, que gerará melhores resultados educacionais.

Logo abaixo dos países que obtiveram eficiência máxima, encontra-se o Chile, que apresenta um score de 0,802 de eficiência. Esse país foi foco de um estudo de Piffaut (2009) cujo resultado afirma que o PIB per capta está negativamente relacionado com a desigualdade de educação. Resultado que vai ao encontro do exposto na Tabela 2, visto que uma eficiência de $80 \%$ é bastante significativa, ou seja, o Chile ainda pode melhorar seus indicadores 
educacionais, entretanto, quando comparado a esse grupo de países, já apresenta bons resultados.

Destaca-se Cuba como sendo o país que apresentou a pior eficiência dentre o grupo analisado, com score de 0,275 . A última colocação de Cuba provavelmente tem relação com o tipo de economia, socialista, que o país apresenta. Mesmo assim, é importante ressaltar que as despesas de Cuba com educação não estão transparecendo em resultados empíricos.

Por isso é importante salientar que conforme comprovado por Hanushek e Woessmann (2008), há fortes indícios de que as habilidades cognitivas da população, oriundas da educação estão fortemente relacionadas com o crescimento econômico. Sendo assim, tanto Cuba, quanto os demais países que não se apresentaram tão eficientes, podem passar a reavaliar suas despesas com educação, com o intuito de gerar mais externalidades.

A partir do cálculo do DEA, pode-se identificar quais países são mais eficientes. Os países ineficientes devem utilizar os benchmarks como referência, no sentido de melhorar os gastos com educação, consequentemente, a eficiência. A Tabela 3 indica os benchmarks para os países latino-americanos ineficientes.

Tabela 3 - Benchmarks dos países ineficientes

\begin{tabular}{l|c}
\hline \multicolumn{1}{c|}{ DMU } & Benchmark (Lambda) \\
\hline Chile & Antígua e Barbuda; Peru; Uruguai \\
\hline México & Guatemala; Peru; Uruguai \\
\hline Colômbia & Guatemala; Peru; Uruguai; Venezuela \\
\hline Paraguai & Barbados; Peru; Uruguai \\
\hline Dominica & Antígua e Barbuda; Peru; Uruguai \\
\hline Bolívia & Peru; Uruguai; Venezuela \\
\hline Costa Rica & Guatemala; Peru; Uruguai \\
\hline Jamaica & Barbados; Peru; Uruguai \\
\hline Argentina & Barbados; Peru; Uruguai \\
\hline Santa Lúcia & Antígua e Barbuda; Peru; Uruguai \\
\hline Belize & Barbados; Peru; Uruguai \\
\hline São Vicente e Granadinas & Barbados; El Salvador; Peru; Uruguai \\
\hline Cuba & Peru; Uruguai \\
\hline Fonte: Dados pesquisa &
\end{tabular}

Fonte: Dados da pesquisa.

Para exemplificar a interpretação dos benchmarks, foi analisado o país de Cuba, uma vez que este foi o mais ineficiente. Ou seja, Cuba deve orientar-se na alocação de recursos públicos na educação pelos países Peru e Uruguai. Assim, os países ineficientes devem basear-se nos países que lhes servem de benchmark, no sentido de estabelecer seus potenciais e planejar suas estratégias de ação para alcançarem maiores níveis de eficiência. Desta forma, criam-se oportunidades para que os gastos em educação dos países ineficientes tenham uma melhora nas taxas brutas, expectativa de vida escolar e na diminuição das reprovações.

Nesse sentido, é possível rejeitar $\mathrm{H} 0$, de que não há diferença de eficiências na alocação de recursos econômicos em relação ao incremento das externalidades positivas na educação dos países da América Central, do Sul e México, visto que apenas 9, dos 22 países analisados apresentaram a mesma eficiência. 
Desse modo, pondera-se que existe grande oscilação na eficiência dos países analisados, o que sugere que aqueles países que apresentam maior eficiência podem evidenciar também maior crescimento, conforme resultados encontrados também na pesquisa de Bils e Klenow (2000).

\section{CONSIDERAÇÕES FINAIS}

Este artigo analisou a alocação de recursos econômicos e externalidades positivas na educação de países da América Central, do Sul e México.

Foi definida uma amostra composta por 22 países, efetuou-se a coleta dos dados utilizados na pesquisa na plataforma UNDATA, disponibilizada no endereço eletrônico da ONU e calculou-se o DEA para mensurar a eficiência proposta no objetivo. Neste sentido, destacam-se 9 países como aqueles que obtiveram eficiência máxima dentre os países analisados, sendo 5 pertencentes a América Central e 4 a América do Sul, resultado que elimina qualquer conclusão generalizável por continente.

O Brasil encontra-se entre os países que obtiveram eficiência máxima, ou seja, é possível afirmar que, para o grupo de países analisados, este país está obtendo tantas externalidades quanto é possível para as despesas que possui com educação.

Ressalta-se que Cuba obteve a menor eficiência da pesquisa, fato que pode ter sua explicação no tipo de economia deste país, que se encontra inserido no regime socialista. Porém, essa justificativa não altera o resultado encontrado, ou seja, Cuba não está eficiente na alocação de recursos econômicos em relação ao incremento das externalidades positivas na educação.

Como limitação de pesquisa, pode ser destacada a amostra utilizada, no qual não abordou todos os países localizados na América, por não estarem disponíveis na base de dados utilizada, com exceção de países como Estados Unidos e Canadá, considerados países desenvolvidos. Recomenda-se que, em trabalhos futuros, seja analisado um grupo maior de países que possuem características culturais semelhantes, seja ampliado o número de variáveis e até mesmo o período de análise. Considerando que foram incluídos países consideravelmente distintos, outra sugestão de pesquisa, sobretudo em aspectos de tamanho de recursos disponíveis, seria a utilização do modelo VRS do DEA.

\section{REFERÊNCIAS}

BANKER, R. D.; CHARNES, A.; COOPER, W. W. Some Models for Estimating Technical and Scale Inefficiencies in Data Envelopment Analysis. Management Science, v. 30, n. 9, 1078-1092. 1984.

BARRO, R. J. Economic Growth in a Cross Section of Countries. Quarterly Journal of Economics, v. 109, n. 2, p. 407-43, May 1991.

BARRO, R. J.; MANKIW, N. G.; SALA-I-MARTIN, X. Capital Mobility in Neoclassical Models of Growth. American Economic Review, v. 85, n. 1, p.103-15, Mar 1995.

BARRO, R. J.; SALA-I-MARTIN, X. Economic growth. New York: McGraw-Hill, 1995.

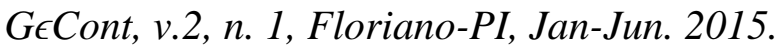


BENHABIB, J.; SPIEGEL, M. M. The Role of Human Capital in Economic Development: Evidence from Aggregate Cross-Country Data. Journal of Monetary Economics, v. 34, n. 2, p. 143-74, 1994.

BILS, M.; KLENOW, P. J. Does Schooling Cause Growth. American Economic Review. v. 90, n. 5, p. 1160-1183, 2000.

CASA NOVA, S. Utilização da análise por envoltória de dados (DEA) na análise das demonstrações contábeis. 2002. 350 f. Tese (Doutorado em Ciências Contábeis) - Programa de Pós-Graduação em Controladoria e Contabilidade, Faculdade de Economia, Administração e Contabilidade, Universidade de São Paulo, São Paulo, 2002.

CHARNES, A.; COOPER, W. W.; RHODES, E. Measuring the Efficiency of Decision Making Units. European Journal of Operational Research. v. 2, n. 6, p. 429-444, 1978.

ERTUR, C.; KOCH, W. Growth, technological interdependence and spatial externalities: theory and evidence. Journal of applied econometrics, v. 22, p. 1033-1062, 2007.

HANUSHEK, E. A.; WOESSMANN, L. The Role of Cognitive Skills in Economic Development. Journal of Economic Literature, v. 46, n. 3, p. 607, Set. 2008.

IRANZO, S.; PERI, G. Schooling Externalities, Technology and Productivity: Theory and Evidence from U.S. States. The Review of Economics and Statistics, v. 91, n. 2; p. 420, May 2009.

KON, A. Subsídios teóricos e metodológicos ao planejamento econômico público. EAESP/FGV/NPP - Núcleo de Pesquisas e Publicações. Relatório de pesquisa nº 12/1997.

LOCHNER, L.; MORETTI, E. The effect of education on crime: evidence from prison inmates, arrests, and self-reports. The American Economic Review, Nashville, v. 94, n. 1, p. 155-189, mar. 2004.

LUCAS, R. E. On the mechanisms of economic development. Journal of Monetary economics, v. 22, p. 3-42, 1988.

MACEDO, M. A. S.; BARbosA, A. C. T. C.; CAVAlCANTE, G. T. C. Desempenho de agências bancárias no Brasil: aplicando análise envoltória de dados (DEA) a indicadores relacionados às perspectivas do BSC. Revista Economia \& Gestão, v. 9, n. 19, 2009.

MARCONI, M. de A.; LAKATOS, E. M. Fundamentos de metodologia científica. 7. ed. São Paulo: Atlas, 2010.

MARE, C.; GRAGOS, C.; POPA, I.; DRAGOS, S.; SPAN, G. How to estimate teaching quality: an overview and some statistical evidences on a sample of master business students in Romania. Studia Universitatis Babes-Bolyai, v. 56, n. 1; p. 98, Abr. 2011.

MARSHALL, A. Princípios de Economia. São Paulo: Nova Cultural, 1984.

MARTINS, G. de A.; THEÓPHILO, C. R. Metodologia da investigação científica para ciências sociais aplicadas. São Paulo: Atlas, 2007.

MARTINS, P. S.; JIN, J. Y. Firm-level social returns to education. Journal of Population Economics, v. 23, n. 2, 2010.

PIFFAUT, V. P. Education and economic growth in Chile. Columbia University, p. 379, 2009. 
PINDICK, R. S.; RUBINFELD, D. L. Microeconomia. São Paulo: Makron Books, 1994.

RODRIGUES, A. S. D. Ensaio sobre a literatura de análise dos efeitos da educação no crescimento econômico. Gestão e Desenvolvimento, v. 12, p. 199-218, 2004.

ROMER, P. Increasing returns and long run growth. Journal of Political Economy, Chicago, n. 94, p. 1002-1037, 1986.

SAMUELSON, P. A. The Pure Theory of Public Expenditure. The Review of Economics and Statistics, v. 36, n. 4, p. 387-389, nov. 1954.

SCARPIN, J. E.; SLOMSKI, V. Estudo dos fatores condicionantes do índice de desenvolvimento humano nos municípios do estado do Paraná: instrumento de controladoria para a tomada de decisões na gestão governamental. Revista Administração Pública, v. 41, n.5, p. 909-933, 2007.

TAYRA, F. RIBEIRO, H. Modelos de indicadores de sustentabilidade: síntese e avaliação das principais experiências. Saúde e Sociedade, v.15, n.1, p.84-95, jan-abr 2006

TOKMAN, A. Educación y crecimiento en Chile. Banco Central de Chile. Documentos de trabajo. 2004.

UNDATA. Disponível em: <http://data.un.org/>. Acesso em 01 de fev. 2012.

VERGARA, S C. Projetos e relatórios de pesquisa em administração. 3. ed. São Paulo: Atlas, 2000. 